\title{
Collateral blood vessels in acute ischemic stroke: a physiological window to predict future outcomes
}

\author{
Circulação colateral no acidente vascular cerebral isquêmico: uma janela fisiológica para \\ prever resultados futuros
}

Heitor Castelo Branco Rodrigues Alves ${ }^{1,2}$, Felipe Torres Pacheco ${ }^{1,2}$, Antonio J. Rocha $a^{1,2}$

\begin{abstract}
Collateral circulation is a physiologic pathway that protects the brain against ischemic injury and can potentially bypass the effect of a blocked artery, thereby influencing ischemic lesion size and growth. Several recent stroke trials have provided information about the role of collaterals in stroke pathophysiology, and collateral perfusion has been recognized to influence arterial recanalization, reperfusion, hemorrhagic transformation, and neurological outcomes after stroke. Our current aim is to summarize the anatomy and physiology of the collateral circulation and to present and discuss a comprehensible review of the related knowledge, particularly the effects of collateral circulation on the time course of ischemic injury and stroke severity, as well as imaging findings and therapeutic implications.
\end{abstract}

Keywords: stroke; brain schemia; collateral circulation; tomography; angiography; perfusion.

\section{RESUMO}

A circulação colateral é um circuito fisiológico de proteção contra alterações isquêmicas que, potencialmente, evita os efeitos de uma oclusão arterial e com isso pode influenciar nas dimensões e no crescimento de uma lesão isquêmica. Vários estudos recentes forneceram informações a respeito do papel das colaterais na fisiopatologia do acidente vascular encefálico isquêmico e demonstraram a capacidade da circulação colateral de influenciar as taxas de reperfusão, recanalização, transformação hemorrágica e com isso desfecho clínico dos pacientes. O objetivo desta revisão é sintetizar a anatomia e a fisiologia da circulação colateral encefálica, apresentando e discutindo, o que se conhece atualmente acerca do seu efeito na cronologia e gravidade da lesão isquêmica, além dos achados de imagens e implicações terapêuticas.

Palavras-chave: acidente vascular cerebral; isquemia encefálica; circulação colateral; tomografia; angiografia; perfusão.

Stroke is the second most common cause of death and was responsible for approximately 6.7 million deaths worldwide in $2012^{1}$. Ischemia, or restricted blood flow, is the main cause of stroke and is typically due to abrupt occlusion of a cerebral artery as a result of progressive atherosclerosis or embolism². Acute ischemic stroke (AIS) can result in severe neurologic disability or death ${ }^{3}$.

Since the late 1990s intravenous thrombolysis has been a recommended treatment for AIS ${ }^{4,5}$. Additionally, in the last decade, several clinical trials have investigated the effects of endovascular treatment (EVT) in the setting of an intracranial or extracranial large artery occlusion. Several studies, including MR CLEAN ${ }^{6}$, ESCAPE ${ }^{3}$, EXTEND-IA ${ }^{7}$ and SWIFT-PRIME, recently proved EVT to be more effective than standard medical care, with or without intravenous thrombolysis, using stentrievers in the majority of the patients in the EVT arms.

However, although EVT has been shown to be generally effective, the trials have documented erratic individual and overall patient outcomes. These differences may not be solely the result of the various methods used but may also be related to patient-specific characteristics' ${ }^{9}$. Among these patientspecific characteristics, collateral status has emerged as an independent factor that is associated with angiographic and clinical outcomes in AIS patients ${ }^{10,11}$.

The collateral circulation is a physiologic pathway of specialized endogenous bypass vessels that is present in most

'Santa Casa de São Paulo, Faculdade de Ciências Médicas, Divisao de Neuroradiologia, São Paulo SP, Brasil;

${ }^{2}$ Fleury Medicina e Saúde, Divisao de Neuroradiologia, São Paulo SP, Brasil.

Correspondence: Antonio Jose da Rocha; Santa Casa de Misericordia de Sao Paulo, Serviço de Diagnostico por Imagem; Rua Dr. Cesario Motta Jr. 112; 01221-020 São Paulo SP, Brasil; E-mail:a.rocha@uol.com.br

Conflict of interest: There are no conflicts of interest to declare.

Received 31 December 2015; Accepted 08 February 2016. 
tissues and protects against ischemic injury during initial oligemic status ${ }^{12}$. In the setting of AIS, the extent of collateral circulation influences the size of the final infarct and the growth of the penumbra. Hence, the relationship between the collateralization grade and the predictability of infarct evolution has been a primary focus in recent years ${ }^{11,13,14}$.

The refinement of diagnostic techniques for evaluation of collateral circulation may contribute to improved anatomical and pathophysiological characterization of this vascular network and its potential therapeutic and prognostic implications ${ }^{15}$. The ability to define physiologic parameters through diagnostic techniques is particularly useful when the time of the stroke is unknown or a wider nonconventional window for treatment is being considered.

In this review, we summarize the basic anatomy and physiology of the collateral circulation and its potential as an endogenous therapeutic target in AIS. The relevance of multidetector computed tomography (MDCT) in clinical settings to support medical decisions regarding AIS is highlighted, and recent evidence indicating that good collateral circulation can prevent or delay permanent neural damage is presented.

\section{THE ANATOMY OF COLLATERAL CIRCULATION}

Two main routes underlie collateral perfusion of the brain parenchyma. The anatomy of this arterial circulation includes extracranial sources of blood flow that can supply intracranial vessels, as well as intracranial routes that can supplement other intracranial areas when pathophysiologic mechanisms become actived ${ }^{15}$.

The extracranial sources consist of large connections between the extracranial and intracranial arteries. The external carotid artery gives rise to many branches in the neck that are potential sources of collateral blood flow, particularly when chronic stenosis or occlusion has developed in the internal carotid artery ${ }^{16}$. The facial, maxillary, middle meningeal, and occipital arteries are the main branches that can shunt flow via anastomoses to the intracranial arteries. Apart from these branches, common anastomotic routes include the ophthalmic artery, which may fill in a retrograde direction, as well as smaller and unnamed dural arteries ${ }^{17}$.

Intracranial collateral routes can be further subdivided into primary and secondary routes. The primary pathways include the permanently active components of the circle of Willis, and the secondary pathways include less direct routes that develop over time. The blood supply to the brain is unique because four major arteries coalesce to form an equalizing distributor, i.e., the circle of Willis, which, despite its variability and asymmetry, can redistribute blood flow in the event of sudden occlusion of a parent vessel.

The secondary pathway comprises leptomeningeal anastomoses that link distal sections of the major cerebral arteries. It has been reported that some small arteriolar connections ( 50-400 $\mu \mathrm{m})$ allow retrograde perfusion of adjacent territories ${ }^{18}$. It is assumed that these connections are important routes for collateral blood flow, especially when an acute arterial occlusion occurs. These arteriolar anastomoses mimic the circle of arteries but connect a much larger extension of the microvasculature, joining territories of the middle cerebral artery (MCA) with both the anterior cerebral artery (ACA) and the posterior cerebral artery (PCA) ${ }^{19}$.

The development of native pial collateral circulation (collaterogenesis), which begins in the embryo, has been shown to determine the extent of the collaterals in adulthood ${ }^{20}$. Acute obstructions induce blood flow across the collateral network (recruitment) followed by remodeling and, potentially, formation of additional collaterals in chronic obstructive disease (neocollateral formation) ${ }^{17}$.

There is wide variation in collateral status among healthy adults, and recent animal studies indicate that genetic background may be a major factor ${ }^{21}$. $\{$ Zhang, $2010 \# 110\}$ A single polymorphic locus on chromosome 7 in mice, i.e., the determinant of collateral extent 1 (Dce1), has been shown to influence the extent of collateralization, blood flow and infarct volume after middle cerebral artery occlusion ${ }^{22}$. Whether human Dcel or related loci are responsible for the wide variation in collateral status in humans is still under investigation.

A number of other factors, including environmental and clinical features, have also been shown to affect the quality and quantity of collaterals (rarefaction) at the time of presentation in AIS. Of these, the strongest predictor by far is age $\mathrm{e}^{23}$. Other clinical features include elevated glucose at the time of presentation, uric acid level, history of hypertension, and history of smoking ${ }^{24,25}$.

\section{PHYSIOLOGY OF COLLATERAL BLOOD FLOW REGULATION}

The importance of the collateral circulation in brain physiology may be demonstrated with the concept of the collaterome, which is an extension of the connectome concept ${ }^{26}$. The collaterome provides a physiologically relevant approach to the management of stroke and the influential balance of collateral perfusion that determines both stroke evolution and related clinical sequelae ${ }^{27}$.

Beyond structural assessments of collateral circulation, advances in perfusion-based imaging have allowed for functional evaluations of the quality of collateral blood flow (effective parenchymal perfusion). Cerebral blood flow $(\mathrm{CBF})$ is regulated by the metabolic demands of the brain itself, which vary regionally and with neuronal activity. Although the precise mechanisms underlying cerebral autoregulation are not fully understood, the process seems to be mediated at several levels and involves neurons, neuropil, and cerebral blood vessels ${ }^{28}$. 
Normal CBF ranges between 50 and $60 \mathrm{~mL} / 100 \mathrm{~g} / \mathrm{min}$ and is tightly controlled by cerebral autoregulation ${ }^{29}$. The pace of cellular death in the brain after an arterial occlusion is closely linked to the severity of the decrease in blood flow within the local environment. When blood flow is less than $10 \mathrm{~mL} / 100 \mathrm{~g} / \mathrm{min}$, damage is rapid, and most cells die within minutes of the insult ${ }^{30,31}$. When CBF is between 10 and $20 \mathrm{~mL} / 100 \mathrm{~g} / \mathrm{min}$ (hypoperfusion), neurons cease to function but remain structurally intact and are potentially revivable if normal blood flow is restored ${ }^{31}$. Therefore, neuronal damage is not uniform when an intracranial artery is occluded, especially in the first few hours after an insult. Depending on the extent of collateral perfusion, infarction may not be complete for hours or even days ${ }^{32}$.

In thrombotic and embolic strokes, the intravascular pressure distal to the occlusion falls immediately. Concurrently, the pressure within the pial vessels is relatively well preserved, resulting in a gradient that is able to promote flow through anastomoses ${ }^{18}$. The effectiveness of collateral vessel flow can be assessed only with measurements of tissue perfusion, which reflect the statuses of both the microcirculation and the macrocirculation. Computed tomography (CT) and magnetic resonance imaging (MRI) perfusion techniques and other methods, such as positron emission tomography (PET) and single-emission computed tomography (SPECT), can provide insight into the collateral flow in patients with cerebrovascular disease ${ }^{17,33,34}$. Physiologically effective collateral perfusion is evident when $\mathrm{CBF}$ and cerebral blood volume (CBV) are maintained within the territory of an occluded artery.

\section{IMAGING OF COLLATERAL VESSELS}

Digital subtraction angiography (DSA) remains the gold standard for the anatomic evaluation of the collateral circulation. This technique allows for the dynamic visualization of blood flow through pial collaterals or other secondary collaterals $^{17,35}$. The main limitations of DSA are its invasive nature, its reliance on iodinated contrast and ionizing radiation, and its inability to evaluate brain parenchyma. Furthermore, performing DSA in AIS when intra-arterial therapy is not considered may generate an additional delay to treatment ${ }^{36}$.

Several noninvasive approaches have been proposed to evaluate intracranial collateral blood flow and the network, but none of these techniques have been shown to be as effective as a reference standard for quantifying collateral flow ${ }^{37}$.

Computed tomography angiography (CTA) is fast, reproducible, and widely available, and its reasonable cost-to-effectiveness ratio makes this technique one of the most widely used methods of evaluating the locations of vascular occlusions and the collateral system. Analysis of CTA source images (CTA-SI) has a higher sensitivity for demonstrating the infarct core than non-contrast computed tomography (NCCT) ${ }^{38}$. Post-processed CTA data involving maximal intensity projections (MIP) and multiplanar reconstruction (MPR) allow for better visualization of the occluded vessel and the extent of leptomeningeal flow ${ }^{39}$. The main limitation of CTA is that it is a snapshot of arterial contrast enhancement, providing limited information about flow dynamics. Some studies have attempted to circumvent this limitation with dual-phase $\mathrm{CTA}^{40}$. Such variations in acquisition protocols and differences in classification have led to low levels of agreement among the relevant results even among experienced observers (K-alpha 0.3-0.6) ${ }^{41}$.

Dynamic CTA has become available for clinical practice in recent years and merges the noninvasive nature of CTA and the dynamic acquisition of DSA. This technique, also referred to as 4D-CTA, enables the noninvasive evaluation of the flow dynamics of the intracranial vasculature by multiple subsequent $\mathrm{CT}$ acquisitions or continuous volume CT acquisition over a period of time ${ }^{42}$.

Several protocols of acquisition have been proposed, including a toggling-table technique, shuttle mode scanning, and volume mode. The volume mode is considered the most versatile option and allows for complete or partial coverage of the whole brain during 1 rotation of the scanner ${ }^{42}$. Dynamic acquisitions in volume mode can be performed discontinuously or continuously, depending on the required temporal resolution. When collateral flow, as in the case of an arterial occlusion, needs to be evaluated, a lower temporal resolution is necessary. In the setting of AIS, 4D-CTA better estimates thrombus burden and the presence of collateral vessels than conventional $\mathrm{CTA}^{42}$. The challenge of the radiation dose level remains, although recently available noise-reduction filters have dramatically reduced radiation exposure ${ }^{43}$.

Magnetic resonance angiography (MRA) using timeof-flight technique (TOF) is one of the most used MR techniques for accessing collateral circulation, but it remains controversial. MRA provides structural information based on flow-sensitive images but is less effective for collateral evaluations than CTA, especially when the objective is to estimate the occlusion of distal branches ${ }^{36,44}$. Contrast-enhanced MRA (CE-MRA) allows better delineation of slow-moving blood in the distal branches and is a better predictor of infarct outcome, but it provides lower spatial resolution ${ }^{44}$.

Transcranial Doppler (TCD) also provides information regarding cerebral autoregulation and cerebral circulation. Flow direction changes, such as those found in the ophthalmic artery, and increased velocity in vessels ipsilateral to a stenosis are correlated with the presence of leptomeningeal collaterals ${ }^{45}$. However considerable variability has been found in TCD performance and interpretation ${ }^{35,45}$.

\section{IMAGING STUDIES OF COLLATERAL CIRCULATION IN THE CLINICAL SETTING OF ACUTE ISCHEMIA}

The concept that a vascular network can potentially bypass the effects of a blocked cerebral artery and influence 
ischemic lesion size and growth ${ }^{37,46}$ has recently had an increased impact on the management of stroke patients ${ }^{4}$.

Assessments of collaterals in angiographic studies have proven be widely variable. A recent meta-analysis by Leng et al. ${ }^{9}$ found 12 studies that used the American Society of Interventional and Therapeutic Neuroradiology/Society of Interventional Radiology (ASITN/SIR) collateral flow grading system by DSA and primarily defined grades 3-4 and 0-2 as good and poor collateral statuses, respectively. Eleven studies have used other grading methods for DSA, 9 studies have used different grading methods for CTA, and others have used CTP or combined grading methods with different imaging modalities.

Two DSA classifications stand out: Higashida ${ }^{47}$ used the ASITN/SIR assessment, which was based on the extent and delay of retrograde filling, whereas Christoforidis ${ }^{48}$ proposed a distinct model that is based solely on the extent of the feedback.

The ASITN/SIR classification ${ }^{47}$ seems to be the most appropriate because it has higher reproducibility and accounts for both the parameters of the extent and the delay of the feedback via collaterals. The ASITN/SIR classification involves a five-point system (Table 1) that has been used in several endovascular trials $s^{9,10,49,50,51,52}$. Grades 0 and 1 indicate only marginal flow, grade 2 indicates only partial filling of the ischemic territory, and grades 3 and 4 indicate varying rates of complete filling of the occluded arterial territory.

Additional non-invasive grading systems for assessing collateral blood flow circulation have also been described ${ }^{53}$. Several strategies have been used to describe CTA-visualized vessels by either comparing them with the contralateral brain hemisphere or estimating the percentage of MCA branches that become filled by contrast media during examination ${ }^{54,55}$.
Souza et al. ${ }^{56}$ proposed a simple and reliable grading system that correlates collateral scores and diffusion-weighted imaging (DWI) lesion volumes on admission.

The best method of evaluating and grading collateral flow remains controversial. The currently proposed methods of assessing collaterals are largely qualitative or semiquantitative, and there are no clear indications of the superiority of any of the available techniques ${ }^{57}$. This lack of consensus may contribute to an overall under appreciation of the fundamental role of collateral circulation in outcomes following AIS.

Nevertheless, Shet and Liebeskind ${ }^{58}$, when revising the status of collateral circulation in endovascular therapy for stroke, concluded that collateral blood supply is pivotal in determining clinical outcomes. In the setting of vascular occlusion, patients with more robust collaterals have smaller infarcts (Figure 1) 17,59 Regardless of the method used to determine the collateral score,

Table 1. American Society of Interventional and Therapeutic Neuroradiology / Society of interventional Radiology (ASITN/SIR) collateral grade scale.

\begin{tabular}{ll} 
Grade & \multicolumn{1}{c}{$\begin{array}{c}\text { Angiographic collaterals } \\
\text { (Digital subtraction angiography) }\end{array}$} \\
\hline $0 \quad$ & $\begin{array}{l}\text { No collaterals visible to the ischemic site } \\
\text { Slow collaterals to the periphery of the ischemic site } \\
\text { with persistence of some of the defect }\end{array}$ \\
& $\begin{array}{l}\text { Rapid collaterals to the periphery of ischemic site with } \\
\text { persistence of some of the defect and to only a portion } \\
\text { of the ischemic territory } \\
\text { Collaterals with slow but complete angiographic blood } \\
\text { flow of the ischemic bed by the late venous phase } \\
\text { Complete and rapid collateral blood flow to the vascular } \\
\text { bed in the entire ischemic territory by retrograde } \\
\text { perfusion }\end{array}$ \\
\hline
\end{tabular}
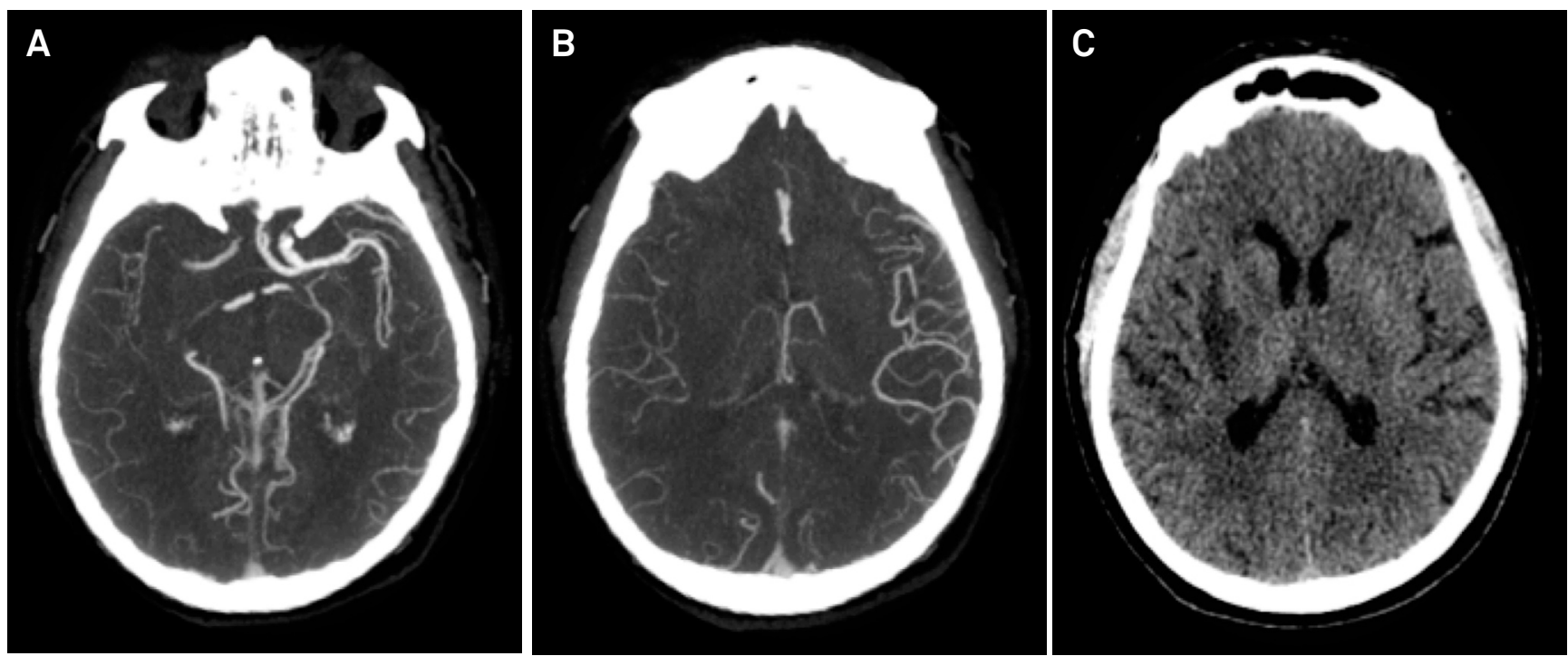

Figure 1. Proximal occlusion with suitable reconstitution of the distal middle cerebral artery (MCA) branches (Mittef grade 3). (A) Computed tomography angiografhy (CTA) identified right MCA occlusion. (B) Note collateral circulation throughout the MCA territory, filled from leptomeningeal branches. (C) Follow-up non-contrast compute tomography (NCCT) 24 hours later demonstrating a small final infarct volume confined to the lenticulostriate territory (proximal MCA); this patient exhibited a good clinical outcome. 
extremely poor outcomes are predicted when collateral blood flow is reduced or absent (Figures 2 and 3) 60,61,62,63. $^{2}$

Physiology is now considered to be more relevant than time in AIS because it is the degree of collateral flow and not simply the time elapsed since the stroke that is the main factor determining core infarct volume within the first 6 hours of stroke on$\operatorname{set}^{46}$. Collateral status is recognized as having an influence on stroke prognosis, particularly in terms of recanalization, reperfusion, hemorrhagic transformation and subsequent neurological outcomes ${ }^{59}$. Collateral grading (Table 2) may represent a currently available opportunity to predict possible future outcomes, whereas elapsed time solely reflects the past and does not have a causal connection with the future of infracted brain tissue.

\section{RELATIONSHIP WITH PARENCHYMAL PERFUSION}

Collaterals are usually evaluated by examining arterial flow with angiography techniques, and parenchymal perfusion is profoundly influenced by downstream microcirculation ${ }^{59}$. The microcirculation is crucial to the restoration of the blood supply to the brain, and collateral circulation may increase ischemic tolerance by enhancing microvascular perfusion ${ }^{35}$.

A relatively simple method of evaluating brain perfusion and viable tissue is the assessment of capillary blush using DSA. The capillary index score (CIS) can define an ischemic area in two ways: either by a lack of anterograde flow (in an area that receives blood supply in a retrograde fashion through pial collaterals) or by a significant delay in anterograde flow due to a proximal partially recanalized $\operatorname{clot}^{64}$. This angiographic index has been shown to be a good predictor of outcomes and a powerful strategy for improving outcomes in endovascular treatment ${ }^{65}$.
Beyond structural assessments, perfusion-based images have allowed functional evaluations to differentiate critically hypoperfused areas (infarct cores), penumbral areas (potentially savable areas) and benign oligemic tissues. Current evidence indicates that the goals of acute stroke treatment should be to determine tissue viability by noninvasive techniques, use this information to individualize thrombolytic therapy, extend the therapeutic time window and rescue penumbral tissue ${ }^{46}$. Therefore, knowing the factors that influence the loss of penumbral tissue is crucial, and collaterals have emerged as a major feature that is relevant to this knowledge.

The presence of robust collaterals both markedly reduces and slows down penumbra loss ${ }^{14}$. This can be seen in patients without significant reperfusion after treatment, reinforcing the fact that poor collaterals alone are able to predict larger infarcts. In contrast, smaller infarcts, at least in part, result from good collaterals. Reperfusion can occur not only via successful recanalization of the primary occlusion and restoration of downstream flow but also via viable collateral blood flow ${ }^{66}$. However, it is important to note that mismatch (the difference between the penumbra and the infarct core) is also an independent prognostic factor with a strong association with better outcomes in target mismatch patients, adding information to the study of collateral profiles ${ }^{67}$.

Some studies have demonstrated the use of ischemiainduced vascular damage estimates in AIS in combination with collateral scores and brain perfusion analysis to predict hemorrhagic complications ${ }^{17,68,69}$. In the setting of poor collaterals, a finding of hyperperfusion may indicate a higher risk of hemorrhagic transformation. When revascularization is achieved, symptomatic hemorrhagic transformation may occur more frequently in patients who have presented with poor collaterals ${ }^{49}$. Higher frequencies of infarct growth and symptomatic hemorrhagic
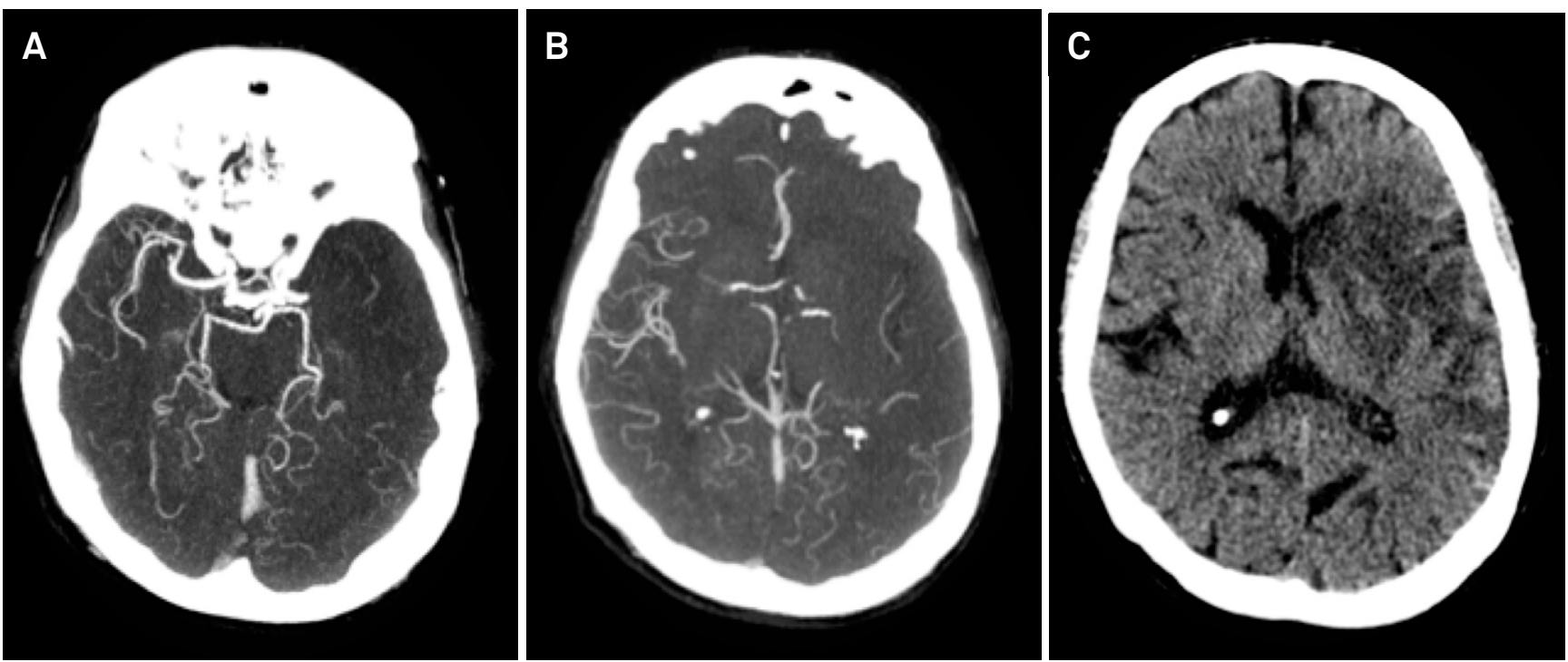

Figure 2. Proximal occlusion with vessel filling restricted to the Sylvian fissure (Mittef grade 2). (A) A left Mittef grade 1 (M1) occlusion was demonstrated on computed tomography angiografhy (CTA), whereas only minimal collateral filling was noted in the middle cerebral artery (MCA) territory (B). (C) Follow-up non-contrast compute tomography (NCCT) 48 hours later illustrating a large infarct volume involving the lenticulostriate territory, insula and temporal lobe. 

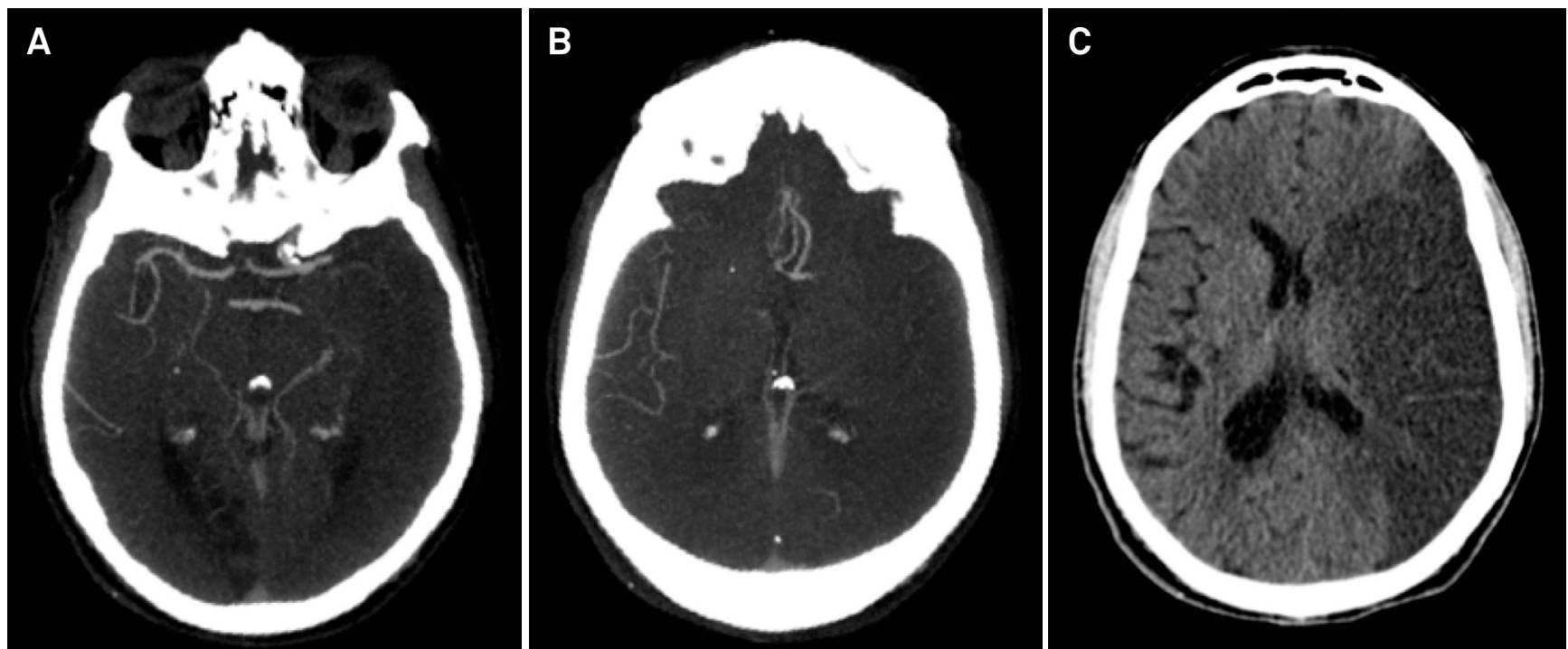

Figure 3. Proximal occlusion with faint contrast opacification restricted to the distal superficial branches (Mittef grade 1 - M1). (A) A left M1 occlusion was found on computed tomography angiografhy (CTA), and the collateral circulation in the middle cerebral artery (MCA) territory was considered absent (B). (C) Follow-up non-contrast compute tomography (NCCT) 24 hours later demonstrating a malignant infarct. This patient died 3 days later.

Table 2. Collateral grade by Miteff system.

\begin{tabular}{ll} 
Grade & Computed tomography angiography collaterals \\
1 & $\begin{array}{l}\text { The contrast opacification is merely seen in the distal } \\
\text { superficial branches }\end{array}$ \\
2 & Vessels can be seen at the Sylvian fissure \\
3 & If the vessels are reconstituted distal to the occlusion \\
\hline
\end{tabular}

transformation in patients with poor collaterals in whom therapeutic recanalization has been achieved may support the concept of reperfusion injury ${ }^{70}$.

\section{TEACHING POINTS FOR CLINICAL USE}

Larger recent trials have established the use of intracranial vascular studies in the setting of AIS to detect proximal obstructions, define the treatment subtype and select an intraarterial approach ${ }^{3,6,7}$. Therefore, the collateral profile should be determined in all of these patients. Some critical findings may be established with the knowledge of collateral status.

Abundant native (preexisting) collateral circulation is directly correlated with better clinical status and smaller volumes of infarcted brain ${ }^{10}$. Improved collateral circulation also predicts higher rates of recanalization, favorable outcomes and lower rates of mortality $9,10,50$.

The absence or relative paucity of a collateral network is a major predictor of extensive infarct on admission ${ }^{56}$, and a proximal thrombus associated with such an absence has been termed a "malignant profile" ${ }^{71}$. Recent studies have also demonstrated that worse collaterals are associated with increased hemorrhagic complications, reinforcing the relevance of specific approaches for these patients ${ }^{49,70}$.

\section{FINAL REMARKS}

This literature review supports the view that noninvasive vascular studies should be used to identify proximal arterial occlusions and to estimate collateral grading in the setting of AIS. A personalized approach that is not solely restricted by time should be provided to maximize the effect of therapy, including appropriate patient selection for EVT.

The currently available knowledge has increased the pathophysiologic understanding of intrinsic compensatory vascular mechanisms, supports the use of MDCT techniques to rapidly evaluate hyperacute AIS, and provides evidence for therapeutic decisions. Modern techniques for reducing radiation exposure should be employed to ensure that diagnostic tests preserve patient safety. 
1. World Health Organization. Global burden of Stroke. Geneva: World Health Organization; 2012 [cited 2015 May 4]. Available from: http://www.who.int/mediacentre/factsheets/fs310/en/

2. Truelsen T, Piechowski-Jóźwiak B, Bonita R, Mathers C, Bogousslavsky J, Boysen G. Stroke incidence and prevalence in Europe: a review of available data. Eur J Neurol. 2006;13(6):581-98. doi:10.1111/j.1468-1331.2006.01138.x

3. Goyal M, Demchuk AM, Menon BK, Eesa M, Rempel JL, Thornton $J$ et al. Randomized assessment of rapid endovascular treatment of ischemic stroke. N Engl J Med. 2015;372(11):1019-30. doi:10.1056/NEJMoa1414905

4. Jauch EC, Saver JL, Adams HP Jr, Bruno A, Connors JJ, Demaerschalk BM et al. Guidelines for the early management of patients with acute ischemic stroke: a guideline for healthcare professionals from the American Heart Association/American Stroke Association. Stroke. 2013;44(3):870-947. doi:10.1161/STR.0b013e318284056a

5. Martins SC, Freitas GR, Pontes-Neto OM, Pieri A, Moro CH, Jesus PA et al. Guidelines for acute ischemic stroke treatment: part II: stroke treatment. Arq Neuropsiquiatr. 2012;70(11):885-93. doi:10.1590/S0004-282X2012001100012

6. Berkhemer OA, Fransen PS, Beumer D, Berg LA, Lingsma HF, Yoo AJ et al. A randomized trial of intraarterial treatment for acute ischemic stroke. N Engl J Med. 2015;372(1):11-20. doi:10.1056/NEJMoa1411587

7. Campbell BC, Mitchell PJ, Kleinig TJ, Dewey HM, Churilov L, Yassi $N$ et al. Endovascular therapy for ischemic stroke with perfusion-imaging selection. N Engl J Med. 2015;372(11):1009-18. doi:10.1056/NEJMoa1414792

8. Saver JL, Goyal M, Bonafe A, Diener HC, Levy El, Pereira VM et al. Solitaire with the Intention for Thrombectomy as Primary Endovascular Treatment for Acute Ischemic Stroke (SWIFT PRIME) trial: protocol for a randomized, controlled, multicenter study comparing the Solitaire revascularization device with IV tPA with IV tPA alone in acute ischemic stroke. Int J Stroke. 2015;10(3):439-48. doi:10.1111/ijs.12459

9. Leng X, Fang H, Leung TW, Mao C, Miao Z, Liu L et al. Impact of collaterals on the efficacy and safety of endovascular treatment in acute ischaemic stroke: a systematic review and meta-analysis. J Neurol Neurosurg Psychiatry. 2015; pii: jnnp-2015-310965. doi:10.1136/jnnp-2015-310965

10. Liebeskind DS, Tomsick TA, Foster LD, Yeatts SD, Carrozzella J, Demchuk AM et al. Collaterals at angiography and outcomes in the Interventional Management of Stroke (IMS) III trial. Stroke. 2014;45(3):759-64. doi:10.1161/STROKEAHA.113.004072

11. Liebeskind DS, Jahan R, Nogueira RG, Zaidat OO, Saver JL, Investigators S. Impact of collaterals on successful revascularization in Solitaire FR with the intention for thrombectomy. Stroke. 2014;45(7):2036-40. doi:10.1161/STROKEAHA.114.00478

12. Faber JE, Chilian WM, Deindl E, Royen N, Simons M. A brief etymology of the collateral circulation. Arterioscler Thromb Vasc Biol. 2014;34(9):1854-9. doi:10.1161/ATVBAHA.114.303929

13. Verma RK, Gralla J, Klinger-Gratz PP, Schankath A, Jung S, Mordasini P et al. Infarction Distribution pattern in acute stroke may predict the extent of leptomeningeal collaterals. PLoS One. 2015;10(9):e0137292. doi:10.1371/journal.pone.0137292

14. Jung S, Gilgen M, Slotboom J, El-Koussy M, Zubler C, Kiefer C et al. Factors that determine penumbral tissue loss in acute ischaemic stroke. Brain. 2013;136(12):3554-60. doi:10.1093/brain/awt246

15. Liebeskind DS. Collateral circulation. Stroke. 2003;34(9):2279-84. doi:10.1161/01.STR.0000086465.41263.06

16. Krishnaswamy A, Klein JP, Kapadia SR. Clinical cerebrovascular anatomy. Catheter Cardiovasc Interv 2010;75(4):530-9.

doi:10.1002/ccd.22299
17. Sheth SA, Liebeskind DS. Imaging evaluation of collaterals in the brain: physiology and clinical translation. Curr Radiol Rep. 2014;2(1):29. doi:10.1007/s40134-013-0029-5

18. Brozici M, Zwan A, Hillen B. Anatomy and functionality of leptomeningeal anastomoses: a review. Stroke. 2003;34(11):2750-62. doi:10.1161/01.STR.0000095791.85737.65

19. Shuaib A, Butcher K, Mohammad AA, Saqqur M, Liebeskind DS. Collateral blood vessels in acute ischaemic stroke: a potential therapeutic target. Lancet Neurol. 2011;10(10):909-21. doi:10.1016/S1474-4422(11)70195-8

20. Lucitti JL, Mackey JK, Morrison JC, Haigh JJ, Adams RH, Faber JE. Formation of the collateral circulation is regulated by vascular endothelial growth factor-A and a disintegrin and metalloprotease family members 10 and 17. Circ Res. 2012;111(12):1539-50. doi:10.1161/CIRCRESAHA.112.279109

21. Zhang H, Prabhakar P, Sealock R, Faber JE. Wide genetic variation in the native pial collateral circulation is a major determinant of variation in severity of stroke. J Cereb Blood Flow Metab. 2010;30(5):923-34. doi:10.1038/jcbfm.2010.10

22. Sealock R, Zhang H, Lucitti JL, Moore SM, Faber JE. Congenic fine-mapping identifies a major causal locus for variation in the native collateral circulation and ischemic injury in brain and lower extremity. Circ Res. 2014;114(4):660-71. doi:10.1161/CIRCRESAHA.114.302931

23. Arsava EM, Vural A, Akpinar E, Gocmen R, Akcalar S, Oguz KK et al. The detrimental effect of aging on leptomeningeal collaterals in ischemic stroke. J Stroke Cerebrovasc Dis. 2014;23(3):421-6. doi:10.1016/j.jstrokecerebrovasdis.2013.03.014

24. Menon BK, Smith EE, Coutts SB, Welsh DG, Faber JE, Goyal $M$ et al. Leptomeningeal collaterals are associated with modifiable metabolic risk factors. Ann Neurol. 2013;74(2):241-8. doi:10.1002/ana.23906

25. Malik N, Hou Q, Vagal A, Patrie J, Xin W, Michel P et al. Demographic and clinical predictors of leptomeningeal collaterals in stroke patients. J Stroke Cerebrovasc Dis. 2014;23(8):2018-22. doi:10.1016/j.jstrokecerebrovasdis.2014.02.018

26. Sporns O, Tononi G, Kötter R. The human connectome: A structural description of the human brain. PLoS Comput Biol. 2005;1(4):e42. doi:10.1371/journal.pcbi.0010042

27. Liebeskind DS. Imaging the collaterome: a stroke renaissance. Curr Opin Neurol. 2015;28(1):1-3. doi:10.1097/WC0.0000000000000171

28. Attwell D, Buchan AM, Charpak S, Lauritzen M, Macvicar BA, Newman EA. Glial and neuronal control of brain blood flow. Nature. 2010;468(7321):232-43. doi:10.1038/nature09613

29. Astrup J, Siesjö BK, Symon L. Thresholds in cerebral ischemia - the ischemic penumbra. Stroke. 1981;12(6):723-5. doi:10.1161/01.STR.12.6.723

30. Sakoh M, Ostergaard L, Gjedde A, Røhl L, Vestergaard-Poulsen P, Smith DF et al. Prediction of tissue survival after middle cerebral artery occlusion based on changes in the apparent diffusion of water. J Neurosurg. 2001;95(3):450-8. doi:10.3171/jns.2001.95.3.0450

31. Sobesky J, Zaro Weber O, Lehnhardt FG, Hesselmann V, Thiel A, Dohmen C et al. Which time-to-peak threshold best identifies penumbral flow? A comparison of perfusionweighted magnetic resonance imaging and positron emission tomography in acute ischemic stroke. Stroke. 2004;35(12):2843-7. doi:10.1161/01.STR.0000147043.29399.f6

32. Hammer MD, Schwamm L, Starkman S, Schellinger PD, Jovin T, Nogueira R et al. Safety and feasibility of NeuroFlo use in eight- to 24-hour ischemic stroke patients. Int J Stroke. 2012;7(8):655-61. doi:10.1111/j.1747-4949.2011.00719.x 
33. Zaharchuk G. Better late than never: the long journey for noncontrast arterial spin labeling perfusion imaging in acute stroke. Stroke. 2012;43(4):931-2. doi:10.1161/STROKEAHA.111.644344

34. Kamano H, Yoshiura T, Hiwatashi A, Abe K, Togao O, Yamashita $\mathrm{K}$ et al. Arterial spin labeling in patients with chronic cerebral artery steno-occlusive disease: correlation with (15)O-PET. Acta Radiol. 2013;54(1):99-106. doi:10.1 258/ar.2012.120450

35. Liu LP, Xu AD, Wong LK, Wang DZ, Wang YJ. Chinese consensus statement on the evaluation and intervention of collateral circulation for ischemic stroke. CNS Neurosci Ther. 2014;20(3):202-8. doi:10.1111/cns.12226

36. Martinon E, Lefevre PH, Thouant P, Osseby GV, Ricolfi F, Chavent A. Collateral circulation in acute stroke: assessing methods and impact: a literature review. J Neuroradiol. 2014;41(2):97-107. doi:10.1016/j.neurad.2014.02.001

37. Wintermark M, Sanelli PC, Albers GW, Bello J, Derdeyn C, Hetts SW et al. Imaging recommendations for acute stroke and transient ischemic attack patients: A joint statement by the American Society of Neuroradiology, the American College of Radiology, and the Society of Neurolnterventional Surgery. AJNR Am J Neuroradiol. 2013;34(11):E117-27. doi:10.3174/ajnr.A3690

38. Pulli B, Yoo AJ. CT angiography source images with modern multisection CT scanners: delay time from contrast injection to imaging determines correlation with infarct core. AJNR Am J Neuroradiol. 2012;33:E61. doi:10.3174/ajnr.A3039

39. Sabarudin A, Subramaniam C, Sun Z. Cerebral CT angiography and CT perfusion in acute stroke detection: a systematic review of diagnostic value. Quant Imaging Med Surg. 2014;4(4):282-90. doi:10.3978/j.issn.2223-4292.2014.07.10

40. Shin NY, Kim KE, Park M, Kim YD, Kim DJ, Ahn SJ et al. Dual-phase CT collateral score: a predictor of clinical outcome in patients with acute ischemic stroke. PLoS One. 2014;9(9):e107379. doi:10.1371/journal.pone.0107379

41. Mair G, Kummer R, Adami A, White PM, Adams ME, Yan B et al. Observer reliability of CT angiography in the assessment of acute ischaemic stroke: data from the Third International Stroke Trial. Neuroradiology. 2015;57(1):1-9. doi:10.1007/s00234-014-1441-0

42. Kortman HG, Smit EJ, Oei MT, Manniesing R, Prokop M, Meijer FJ. 4D-CTA in neurovascular disease: a review. AJNR Am J Neuroradiol. 2015;36(6):1026-33. doi:10.3174/ajnr.A4162

43. Mendrik AM, Vonken EJ, Ginneken B, Jong HW, Riordan A, Seeters T et al. TIPS bilateral noise reduction in 4D CT perfusion scans produces high-quality cerebral blood flow maps. Phys Med Biol. 2011;56(13):3857-72. doi:10.1088/0031-9155/56/13/008

44. Ernst M, Forkert ND, Brehmer L, Thomalla G, Siemonsen S, Fiehler $J$ et al. Prediction of infarction and reperfusion in stroke by flow- and volume-weighted collateral signal in MR angiography. AJNR Am J Neuroradiol. 2015;36(2):275-82. doi:10.3174/ajnr.A4145

45. Aries MJ, Elting JW, De Keyser J, Kremer BP, Vroomen PC. Cerebral autoregulation in stroke: a review of transcranial Doppler studies. Stroke. 2010;41(11):2697-704. doi:10.1161/STROKEAHA.110.594168

46. Cheng-Ching E, Frontera JA, Man S, Aoki J, Tateishi Y, Hui FK et al. Degree of collaterals and not time is the determining factor of core infarct volume within 6 hours of stroke onset. AJNR Am J Neuroradiol. 2015;36(7):1272-6. doi:10.3174/ajnr.A4274

47. Higashida RT, Furlan AJ, Roberts H, Tomsick T, Connors B, Barr J et al. Trial design and reporting standards for intra-arterial cerebral thrombolysis for acute ischemic stroke. Stroke. 2003;34(8):e109-37. doi:10.1161/01.STR.0000082721.62796.09

48. Christoforidis GA, Mohammad Y, Kehagias D, Avutu B, Slivka AP. Angiographic assessment of pial collaterals as a prognostic indicator following intra-arterial thrombolysis for acute ischemic stroke. AJNR Am J Neuroradiol. 2005;26(7):1789-97.

49. Liebeskind DS, Jahan R, Nogueira RG, Jovin TG, Lutsep HL, Saver $\mathrm{JL}$. Early arrival at the emergency department is associated with better collaterals, smaller established infarcts and better clinical outcomes with endovascular stroke therapy: SWIFT study. J Neurointerv Surg. 2015; pii:neurintsurg-2015-011758. doi:10.1136/neurintsurg-2015-011758

50. Singer OC, Berkefeld J, Nolte CH, Bohner G, Reich A, Wiesmann $M$ et al. Collateral vessels in proximal middle cerebral artery occlusion: the ENDOSTROKE study. Radiology. 2015;274(3):851-8. doi:10.1148/radiol.14140951

51. Hwang YH, Kang DH, Kim YW, Kim YS, Park SP, Liebeskind DS. Impact of time-to-reperfusion on outcome in patients with poor collaterals. AJNR Am J Neuroradiol. 2015;36(3):495-500. doi:10.3174/ajnr.A4151

52. Singer OC, Berkefeld J, Nolte CH, Bohner G, Haring HP, Trenkler $J$ et al. Mechanical recanalization in basilar artery occlusion: the ENDOSTROKE study. Ann Neurol. 2015;77(3):415-24. doi:10.1002/ana.24336

53. McVerry F, Liebeskind DS, Muir KW. Systematic review of methods for assessing leptomeningeal collateral flow. AJNR Am J Neuroradiol. 2012;33(3):576-82. doi:10.3174/ajnr.A2794

54. Schramm P, Schellinger PD, Fiebach JB, Heiland S, Jansen O, Knauth $\mathrm{M}$ et al. Comparison of CT and CT angiography source images with diffusion-weighted imaging in patients with acute stroke within 6 hours after onset. Stroke. 2002;33(10):2426-32. doi:10.1161/01.STR.0000032244.03134.37

55. Tan JC, Dillon WP, Liu S, Adler F, Smith WS, Wintermark M. Systematic comparison of perfusion-CT and CT-angiography in acute stroke patients. Ann Neurol. 2007;61(6):533-43. doi:10.1002/ana.21130

56. Souza LC, Yoo AJ, Chaudhry ZA, Payabvash S, Kemmling A, Schaefer PW et al. Malignant CTA collateral profile is highly specific for large admission DWI infarct core and poor outcome in acute stroke. AJNR Am J Neuroradiol. 2012;33(7):1331-6. doi:10.3174/ajnr.A2985

57. Yeo LL, Paliwal P, Teoh HL, Seet RC, Chan BP, Ting E et al. Assessment of intracranial collaterals on CT angiography in anterior circulation acute ischemic stroke. AJNR Am J Neuroradiol. 2015;36(2):289-94. doi:10.3174/ajnr.A4117

58. Sheth SA, Liebeskind DS. Collaterals in endovascular therapy for stroke. Curr Opin Neurol. 2015;28(1):10-5. doi:10.1097/WC0.0000000000000166

59. Liebeskind DS. Collateral lessons from recent acute ischemic stroke trials. Neurol Res. 2014;36(5):397-402. doi:10.1179/1743132814Y.0000000348

60. Miteff F, Levi CR, Bateman GA, Spratt N, McElduff P, Parsons $\mathrm{MW}$. The independent predictive utility of computed tomography angiographic collateral status in acute ischaemic stroke. Brain. 2009;132(8):2231-8. doi:10.1093/brain/awp155

61. Maas MB, Lev MH, Ay H, Singhal AB, Greer DM, Smith WS et al. Collateral vessels on CT angiography predict outcome in acute ischemic stroke. Stroke. 2009;40(9):3001-5. doi:10.1161/STROKEAHA.109.552513

62. Tan IY, Demchuk AM, Hopyan J, Zhang L, Gladstone D, Wong $K$ et al. CT angiography clot burden score and collateral score: correlation with clinical and radiologic outcomes in acute middle cerebral artery infarct. AJNR Am J Neuroradiol. 2009;30(3):525-31. doi:10.3174/ajnr.A1408

63. Menon BK, Smith EE, Modi J, Patel SK, Bhatia R, Watson TW et al. Regional leptomeningeal score on CT angiography predicts clinical and imaging outcomes in patients with acute anterior circulation occlusions. AJNR Am J Neuroradiol. 2011;32(9):1640-5. doi:10.3174/ajnr.A2564

64. Al-Ali F, Jefferson A, Barrow T, Cree T, Louis S, Luke K et al. The capillary index score: rethinking the acute ischemic stroke treatment algorithm. Results from the Borgess Medical Center Acute Ischemic Stroke Registry. J Neurointerv Surg. 2013;5(2):139-43. doi:10.1136/neurintsurg-2011-010146 
65. Al-Ali F, Elias JJ, Tomsick TA, Liebeskind DS, Broderick JP. Relative Influence of Capillary Index Score, Revascularization, and Time on Stroke Outcomes From the Interventional Management of Stroke III Trial. Stroke. 2015;46L6)1590-4. doi:10.1161/STROKEAHA.115.009066

66. Soares BP, Chien JD, Wintermark M. MR and CT monitoring of recanalization, reperfusion, and penumbra salvage: everything that recanalizes does not necessarily reperfuse! Stroke. 2009;40(3 Suppl 1):S24-7. doi:10.1161/STROKEAHA.108.526814

67. Spiessberger A, Federau C, Guggenberger R, Kollias S. Influence of leptomeningeal collateral pattern on the prognostic value of mismatch in acute anterior circulation stroke. J Comput Assist Tomogr. 2015;39(2):213-6. doi:10.1097/RCT.0000000000000204

68. Hom J, Dankbaar JW, Soares BP, Schneider T, Cheng SC, Bredno $J$ et al. Blood-brain barrier permeability assessed by perfusion
CT predicts symptomatic hemorrhagic transformation and malignant edema in acute ischemic stroke. AJNR Am J Neuroradiol. 2011;32(1):41-8. doi:10.3174/ajnr.A2244

69. Jain AR, Jain M, Kanthala AR, Damania D, Stead LG, Wang HZ et al. Association of CT perfusion parameters with hemorrhagic transformation in acute ischemic stroke. AJNR Am J Neuroradiol. 2013;34(10):1895-900. doi:10.3174/ajnr.A3502

70. Bang OY, Saver JL, Kim SJ, Kim GM, Chung CS, Ovbiagele $B$ et al. Collateral flow predicts response to endovascular therapy for acute ischemic stroke. Stroke. 2011;42(3):693-9. doi:10.1161/STROKEAHA.110.595256

71. Saarinen JT, Rusanen H, Sillanpää N. Collateral score complements clot location in predicting the outcome of intravenous thrombolysis. AJNR Am J Neuroradiol. 2014;35(10):1892-6. doi:10.3174/ajnr.A3983 